\title{
Transapical JenaValve in a degenerated Freedom SOLO bioprosthesis
}

\author{
Laurens Willem Wollersheim, MD, Riccardo Cocchieri, MD, Petr Symersky, MD, PhD, and
}

Bas A. de Mol, BA, MD, PhD, Amsterdam, The Netherlands

Degeneration of an aortic bioprosthesis is a complication often requiring high-risk surgical reintervention. Transcatheter aortic valve implantation (TAVI) provides an alternative to high-risk surgery. However, TAVI for a degenerated stentless bioprosthesis becomes more perilous because of the lack of support of a stent and the changed landmarks of the aortic root. Furthermore, the supraannular implantation technique for the stentless Freedom SOLO (Sorin Group, Milan, Italy) bioprosthesis may increase the risk for coronary occlusion after deployment because of the reduced distance between the neoannulus and the coronary ostia. In this setting, the use of the JenaValve (JenaValve Technology, GmbH, München, Germany) could reduce the risk of coronary ostium obstruction because of the specific design of this device. To illustrate this clinical problem, we present the first reported case after successful transcatheter valve-in-valve implantation of a JenaValve in a degenerated Freedom SOLO.

\section{CLINICAL SUMMARY}

An 86-year-old woman presented with progressive dyspnea on exertion. Her medical history included hypertension, chronic obstructive pulmonary disease, and aortic valve replacement (Freedom SOLO $23 \mathrm{~mm}$ ) for aortic valve stenosis 7 years previously. Transthoracic echocardiography showed severe aortic valve stenosis with a maximum gradient of $103 \mathrm{~mm} \mathrm{Hg}$ and a mean gradient of $65 \mathrm{~mm} \mathrm{Hg}$ over the Freedom SOLO, with an aortic valve area of $0.6 \mathrm{~cm}^{2}$. The logistic European System for Cardiac Operative Risk Evaluation score was $36.5 \%$, and the Society of Thoracic Surgeons score was $6.3 \%$. The distance, measured on a computed tomography scan (Figure 1),

\footnotetext{
From the Division of Cardiothoracic Surgery, Academic Medical Center Amsterdam, Amsterdam, The Netherlands.

Disclosures: Dr Cocchieri reports a proctorship and lecture fees from Edwards Lifesciences. All other authors have nothing to disclose with regard to commercial support.

Drs Wollersheim and Cocchieri share first authorship.

Received for publication Jan 22, 2014; revisions received Feb 27, 2014; accepted for publication March 12, 2014; available ahead of print April 14, 2014

Address for reprints: Laurens Willem Wollersheim, MD, Academic Medical Center Amsterdam, Cardiothoracic Surgery, Meibergdreef 9, 1105 AZ Amsterdam, The Netherlands (E-mail: 1.w.wollersheim@amc.nl).

J Thorac Cardiovasc Surg 2014;148:741-2

$0022-5223 / \$ 36.00$

Copyright (C) 2014 by The American Association for Thoracic Surgery

http://dx.doi.org/10.1016/j.jtcvs.2014.03.017
}

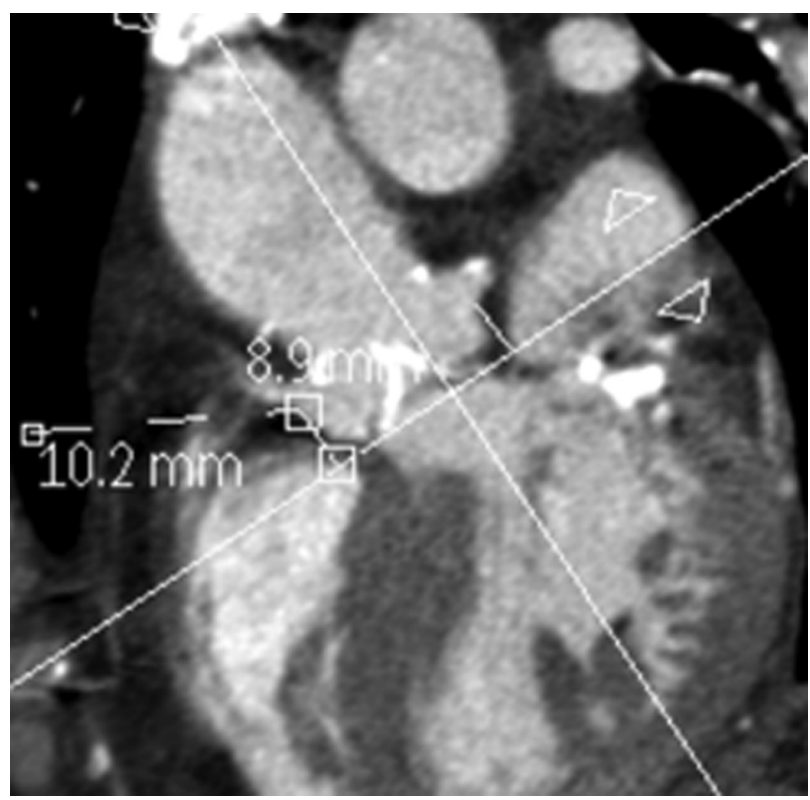

FIGURE 1. Reconstruction of the aortic root with measurements of the distance between the coronary ostia and the supra-annular Freedom SOLO (Sorin Group, Milan, Italy).

between the leaflets' base and the coronary ostia was 10 $\mathrm{mm}$ and $9 \mathrm{~mm}$ for the right and left coronary ostia, respectively. Because of the short distance between the coronary ostia and the neoannulus of the Freedom SOLO, the JenaValve was preferred to reduce the risk of coronary occlusion.

Access to the left ventricular apex was achieved through an anterolateral mini-thoracotomy in the fifth intercostal space. Once the ideal muscular spot was identified, a double Prolene suture with pledgets and an epicardial pacing lead were placed. Balloon valvuloplasty was performed under rapid pacing. A $25-\mathrm{mm}$ JenaValve was positioned in the Freedom SOLO, and the positioning feelers were released and verified for anatomic orientation in the nadirs of each of the 3 leaflets (Figure 2, A). Correct positioning was verified under fluoroscopy, and the lower part of the stent was released. The leaflets of the Freedom SOLO were clipped onto the JenaValve while the valve unfolded (Figure 2, $B$ ). Subsequently, the upper part of the JenaValve was completely deployed (Figure 2, C). Transesophageal echocardiography showed good function of the JenaValve with a Vmax of $3 \mathrm{~m} / \mathrm{s}$, a mean gradient of $16 \mathrm{~mm} \mathrm{Hg}$, and an aortic 

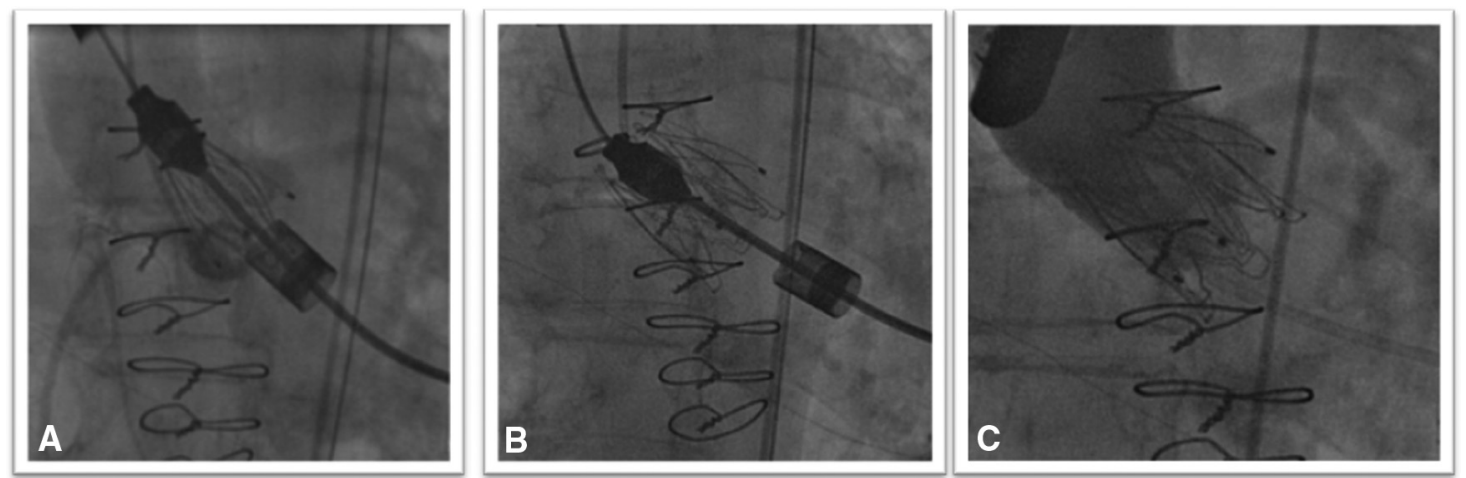

FIGURE 2. A, Anatomic orientation with the released positioning feelers, positioned in the nadirs of the leaflets. B, Lower part of the JenaValve (JenaValve Technology, GmbH, München, Germany) released. Leaflets are clipped. C, The completely deployed JenaValve without aortic regurgitation.

valve area of $1.2 \mathrm{~cm}^{2}$, and no paravalvular leakage or aortic insufficiency. The postoperative period was uneventful. The patient was discharged in good condition to a cardiology unit in a regional hospital near her home on postoperative day 6.

\section{DISCUSSION}

The Freedom SOLO is a stentless aortic bioprosthesis implanted supra-annularly using only 1 running suture line in the sinuses of Valsalva. Early malfunction of a Freedom SOLO is rare, with only 3 reported cases in the known literature. ${ }^{1-3}$ This is the first reported case in which the risk for surgical reintervention was deemed too high and TAVI was found to be an attractive alternative. However, according to the European guidelines, an elevated risk of coronary artery ostium obstruction, in case of a short distance between the aortic annulus and the coronary ostium, is an absolute contraindication for TAVI. ${ }^{4}$ Al-Lamee and colleagues ${ }^{5}$ suggest that the height of coronary ostia shorter than $10 \mathrm{~mm}$ from the base of the aortic valve leaflets should be an overall contraindication for TAVI, to prevent coronary arterial occlusion We believe that this risk could be attenuated because of the specific design of the JenaValve. The JenaValve is a self-deploying nitinol prosthesis with an anchoring mechanism that resembles a 3-foil paperclip and grasps each of the leaflets. For deployment, 3 feelers are first positioned in each of the 3 nadirs of the leaflets, after which the lower part of the fixation mechanism clasps the internal side of the aortic valve cusps for anchoring. This allows anatomically correct positioning, preventing coronary ostium obstruction. Furthermore, because of the active clip fixation, there could be a lower risk of valve migration toward the coronary ostia during expansion of the JenaValve compared with other transcatheter valves. The minimal coronary height required for placement of the JenaValve is $8 \mathrm{~mm}$.

\section{CONCLUSIONS}

We support the use of the JenaValve when a transcatheter valve-in-valve implantation is required in a degenerated Freedom SOLO to reduce the risk of coronary ostium obstruction.

\section{References}

1. Giordano V, Hermens JA, Wajon EM, Grandjean JG. Rare prosthesis failure after aortic valve replacement with a Freedom SOLO. Interact Cardiovasc Thorac Surg. 2011;12:273-5

2. Wollersheim LW, Li WW, van der Meulen J, de Mol BA. A 76-year old man with a torn Freedom SOLO bioprosthesis. Interact Cardiovasc Thorac Surg. 2014;18: $141-2$.

3. Caprili L, Fahim AN, Zussa C, Cristell DM. Very early malfunction of a large stentless aortic valve. Eur J Cardiothorac Surg. 2009;36:417-8.

4. Vahanian A, Alfieri O, Andreotti F, Antunes MJ, Barón-Esquivias G, Baumgartner H, et al. Guidelines on the management of valvular heart disease (version 2012). Eur Heart J. 2012;33:2451-96.

5. Al-Lamee R, Godino C, Colombo A. Transcatheter aortic valve implantation: current principles of patient and technique selection and future perspectives. Circ Cardiovasc Interv. 2011;4:387-95. 